\title{
Associations between endothelin polymorphisms and aneurysmal subarachnoid hemorrhage, clinical vasospasm, delayed cerebral ischemia, and functional outcome
}

\author{
Christoph J. Griessenauer, MD, ${ }^{1}$ Robert M. Starke, MD, MSc, ${ }^{2}$ Paul M. Foreman, MD, ${ }^{3}$ \\ Philipp Hendrix, MD, ${ }^{4}$ Mark R. Harrigan, MD, ${ }^{3}$ Winfield S. Fisher III, MD, ${ }^{3}$ Nilesh A. Vyas, MD, ${ }^{5}$ \\ Robert H. Lipsky, PhD, ${ }^{5,6}$ Mingkuan Lin, PhD, ${ }^{6}$ Beverly C. Walters, MD, MSc, FRCSC, ${ }^{3,5,6}$ \\ Jean-Francois Pittet, MD, ${ }^{7}$ and Mali Mathru, MD
}

${ }^{1}$ Beth Israel Deaconess Medical Center, Harvard Medical School, Boston, Massachusetts; ${ }^{2}$ Department of Neurosurgery and Radiology, University of Miami, Florida; ${ }^{3}$ Department of Neurosurgery, University of Alabama at Birmingham, Alabama; ${ }^{4}$ Department of Neurosurgery, Saarland University Medical Center and Saarland University Faculty of Medicine, Homburg/Saar, Germany; ${ }^{5}$ Department of Neurosciences, Inova Health System, Falls Church, Virginia; ${ }^{6}$ Department of Molecular Neuroscience, George Mason University, Fairfax, Virginia; and 'Department of Anesthesiology, University of Alabama at Birmingham, Alabama

OBJECTIVE Endothelin-1, a potent vasoconstrictor, and its receptors may be involved in the pathogenesis of aneurysmal subarachnoid hemorrhage (aSAH), clinical vasospasm, delayed cerebral ischemia (DCl), and functional outcome following aSAH. In the present study, common endothelin single nucleotide polymorphisms (SNPs) and their relation to aSAH were evaluated.

METHODS Blood samples from all patients enrolled in the Cerebral Aneurysm Renin Angiotensin System (CARAS) study were used for genetic evaluation. The CARAS study prospectively enrolled patients with aSAH at 2 academic institutions in the US from 2012 to 2015. Common endothelin SNPs were detected using 5' exonnuclease (TaqMan) genotyping assays. Analysis of associations between endothelin SNPs and aSAH and its clinical sequelae was performed.

RESULTS Samples from 149 patients with aSAH and 50 controls were available for analysis. In multivariate logistic regression analysis, the TG (odds ratio [OR] 2.102, 95\% confidence interval [Cl] 1.048-4.218, $p=0.036$ ) and TT genotypes (OR 7.884, 95\% Cl 1.003-61.995, $p=0.05$ ) of the endothelin-1 T/G SNP (rs1800541) were significantly associated with aSAH. There was a dominant effect of the $\mathrm{G}$ allele (CG/GG genotypes; OR 4.617, 95\% Cl 1.311-16.262, $p=0.017$ ) of the endothelin receptor A G/C SNP (rs5335) on clinical vasospasm. Endothelin SNPs were not associated with DCl or functional outcome.

CONCLUSIONS Common endothelin SNPs were found to be associated with presentation with aSAH and clinical vasospasm. Further studies are required to elucidate the relevant pathophysiology and its potential implications in the treatment of patients with aSAH.

https://thejns.org/doi/abs/10.3171/2016.12.JNS162594

KEY WORDS endothelin; polymorphism; aneurysm; cerebral; intracranial; subarachnoid hemorrhage; vasospasm; delayed cerebral ischemia; rupture; vascular disorders

A NEURYSMAL subarachnoid hemorrhage (aSAH) is the common end point of environmental, biomechanical, cellular, molecular, and genetic processes that underlie the formation and rupture of cerebral aneurysms. Genetic polymorphisms have been associated with aSAH and its sequelae, clinical vasospasm, and delayed cerebral ischemia (DCI). ${ }^{19}$ Endothelin-1 (END1), a potent vasoconstrictor, and its receptors may be com-

ABBREVIATIONS aSAH = aneurysmal subarachnoid hemorrhage; CARAS = Cerebral Aneurysm Renin Angiotensin System; $\mathrm{Cl}=$ confidence interval; CONSCIOUS = Clazosentan to Overcome Neurological Ischemia and Infarct Occurring after Subarachnoid Hemorrhage; $\mathrm{CTA}=\mathrm{CT}$ angiography; $\mathrm{DCl}=$ delayed cerebral ischemia; $\mathrm{DSA}=$ digital subtraction angiography; END1 = endothelin-1; ENDRA = endothelin receptor A; ENDRB = endothelin receptor B; ICU = intensive care unit; $m$ RS = modified Rankin scale; NO = nitric oxide; OR = odds ratio; SNP = single nucleotide polymorphism; TCD = transcranial Doppler ultrasonography.

SUBMITTED October 20, 2016. ACCEPTED December 5, 2016.

INCLUDE WHEN CITING Published online May 26, 2017; DOI: 10.3171/2016.12.JNS162594. 
ponents in this complex multifactorial process and have been investigated as therapeutic targets in aSAH. The purpose of the present study was to investigate associations of single nucleotide polymorphisms (SNPs) of END1 and endothelin receptors A (ENDRA) and B (ENDRB) encoding genes with aSAH. The majority of these SNPs have been studied in the context of ischemic stroke ${ }^{22}$ but not in aSAH.

\section{Methods}

Blood samples from all patients and controls enrolled in the Cerebral Aneurysm Renin Angiotensin System (CARAS) study were used for genetic evaluation; much of the method has previously been reported..$^{5-7,9,10}$ In the CARAS study, the diagnosis of aSAH was established on the basis of the admission CT scan or xanthochromia of CSF. A ruptured aneurysm as the source of hemorrhage was confirmed by CT angiography (CTA) or digital subtraction angiography (DSA). Exclusion criteria were age under 19 years and any associated genetic predisposition that could contribute to cerebral aneurysm formation (polycystic kidney disease, Turner syndrome, Noonan syndrome, Ehler-Danlos syndrome Type 4, Marfan syndrome, neurofibromatosis Type 1, etc.). The control group was composed of trauma patients, at least 19 years old, with unremarkable CT angiograms of the head and neck (no cerebral aneurysm or other vascular malformation), and without known genetic risk factors for cerebral aneurysm formation. Controls underwent CTA due to suspicion for traumatic cerebrovascular injury. Patients with any abnormalities of the cerebral vasculature were excluded. Efforts were made to match aSAH patients and controls for age and sex. Both aSAH patients and controls were enrolled within 72 hours of admission.

\section{General Management}

Patients were treated in accordance with guidelines for the management of aSAH, including intensive care unit (ICU) monitoring, treatment of hydrocephalus, early ( $<48$-hour) intervention for aneurysm treatment, oral nimodipine, maintenance of euvolemia, and surveillance for clinical vasospasm and DCI. ${ }^{2}$

\section{Definition of Clinical Vasospasm and DCI}

Clinical vasospasm was defined as a new focal or global neurological deficit, or deterioration of at least 2 points on the Glasgow Coma Scale, not explained by another clinical process including hydrocephalus, aneurysm rebleeding, electrolyte disturbance, seizure, infection, fever, metabolic disturbance, cerebral edema, or surgical complication. Corroborating evidence of angiographic vasospasm was defined as arterial narrowing on CTA or DSA not due to atherosclerosis, catheter-induced vasospasm, or vessel hypoplasia. Additionally, vasospasm was diagnosed with transcranial Doppler ultrasonography (TCD) findings of a mean systolic middle cerebral artery (MCA) pressure of more than $120 \mathrm{~cm} / \mathrm{sec}$ with a Lindegaard ratio more than 3. CTA, DSA, and TCD were obtained at the discretion of the treating neurosurgeon. The diagnosis of clinical vasospasm was adjudicated by consensus of the study team and treated with hyperdynamic therapy as the first line of treatment. ${ }^{3}$ Hyperdynamic therapy included avoidance of hypovolemia with a goal systolic blood pressure of more than $160 \mathrm{~mm} \mathrm{Hg}$, accomplished with either permissive hypertension or vasopressor therapy. Patients with clinical vasospasm refractory to medical treatment were treated in the endovascular suite at the discretion of the treating neurosurgeon.

CT or MRI was routinely performed when the patient was transferred from the ICU to the ward. DCI was defined as low-density areas on CT that corresponded to a vascular distribution, or MRI demonstrating a hyperintense area on a diffusion-weighted imaging sequence with a corresponding hypointense apparent diffusion coefficient sequence correlate that corresponded with a vascular territory. Infarctions or contusions noted on postoperative Day 1 imaging were considered procedurally related and were not considered DCI. Images were evaluated locally and blinded to the genetic analysis.

\section{Outcome Measures in Patients With aSAH}

Outcome measures included clinical vasospasm, DCI, and functional outcome at the time of discharge from the acute hospital setting, and at last follow-up using the modified Rankin scale (mRS). Unfavorable outcome was defined as mRS score 3-6. All outcome data were obtained blinded to the results of the genetic analysis. Functional outcome was assessed either in clinic or via telephone interview with the patient or with a surrogate if the patient was unable to participate.

\section{Laboratory and Genetic Evaluation}

Common endothelin SNPs (Table 1) were detected using $5^{\prime}$ exonnuclease (TaqMan) genotyping assays (SNPs END1 [rs1800541, rs2070699, rs5370; Lys198Asn, K198N], ENDRA [rs1801708, rs5333, rs5335], and ENDRB [rs3818416, rs5351]; http://useast.ensembl.org/ Homo_sapiens/Info/Index). Commercial TaqMan assays were designed and performed according to the vendor (Thermo Fisher Scientific, Inc.). Approximately 10\% of the DNA samples were randomly selected to test reproducibility of TaqMan assays. All of the replication samples produced concordant genotypes.

\section{Statistical Analysis}

Continuous variables are presented as means \pm standard deviations and categorical variables are presented as frequencies and percentages. Analyses were performed using unpaired Wilcoxon rank-sum, chi-square, and Fisher's exact tests, as well as the Student t-test, as appropriate. Patient characteristics and endothelin SNPs were tested in univariate analysis to determine predictors of aSAH. Patient and aneurysm characteristics and endothelin SNPs were tested in univariate analysis to determine predictors of the following dependent variables: clinical vasospasm, DCI, and unfavorable functional outcome at discharge (mRS score 3-6) and at follow-up. Factors predictive in univariate analysis $(\mathrm{p}<0.15)$ were entered into a multivariate logistic regression analysis; $p$ values $\leq 0.05$ were considered statistically significant. 
TABLE 1. Common endothelin SNPs

\begin{tabular}{cccc}
\hline \multicolumn{1}{c}{ Gene name } & \multicolumn{1}{c}{$\begin{array}{c}\text { rsID } \\
\text { (variant) }\end{array}$} & Alleles & $\begin{array}{c}\text { Minor Allele } \\
\text { Frequency* }\end{array}$ \\
\hline Endothelin 1 (END1) & rs1800541 & T/G & $0.28(\mathrm{G})$ \\
\hline Endothelin 1 (END1) & rs2070699 & $\mathrm{G} / \mathrm{T}$ & $0.36(\mathrm{~T})$ \\
\hline $\begin{array}{l}\text { Endothelin 1 (END1) } \\
\text { Ks5370 (Lys198Asn, } \\
\text { K198N) }\end{array}$ & $\mathrm{G} / \mathrm{T}$ & $0.25(\mathrm{~T})$ \\
\hline $\begin{array}{c}\text { Endothelin receptor A } \\
\text { (EDNRA) }\end{array}$ & $\mathrm{rs1801708}$ & $\mathrm{G} / \mathrm{A}$ & $0.48(\mathrm{G})$ \\
\hline $\begin{array}{c}\text { Endothelin receptor A } \\
\text { (EDNRA) }\end{array}$ & $\mathrm{rs5333}$ & $\mathrm{T} / \mathrm{C}$ & $0.38(\mathrm{C})$ \\
\hline $\begin{array}{c}\text { Endothelin receptor A } \\
\text { (EDNRA) }\end{array}$ & $\mathrm{rs5335}$ & $\mathrm{G} / \mathrm{C}$ & $0.42(\mathrm{G})$ \\
\hline $\begin{array}{c}\text { Endothelin receptor B } \\
\text { (EDNRB) }\end{array}$ & $\mathrm{rs3818416}$ & $\mathrm{A} / \mathrm{C}$ & $0.22(\mathrm{~A})$ \\
\hline $\begin{array}{c}\text { Endothelin receptor B } \\
\text { (EDNRB) }\end{array}$ & $\mathrm{rs5351}$ & $\mathrm{T} / \mathrm{C} / \mathrm{G}$ & $0.46(\mathrm{~T})$ \\
\hline
\end{tabular}

* http://useast.ensembl.org/Homo_sapiens//nfo/Index?redirect=no.

\section{Results}

Blood samples were analyzed from 149 patients with aSAH and 50 controls enrolled between September 2012 and February 2015.

\section{Characteristics of Patients and Controls}

The mean ages of aSAH patients and controls were $54.9 \pm 12.5$ and $50.6 \pm 18.6$ years, respectively $(\mathrm{p}=0.07)$. There was a higher proportion of African Americans in the aSAH group as compared with the control group ( $p$ $=0.003)$. Sex was evenly distributed between the two groups $(\mathrm{p}=0.086)$. A history of hypertension $(\mathrm{p}=0.013)$ and a family history of cerebral aneurysms $(p=0.025)$ were more frequent in the aSAH group. There was no difference in the rate of current or former smokers $(\mathrm{p}=$ $0.426)$. The majority of ruptured aneurysms were less than $7 \mathrm{~mm}$ in maximum diameter $(62.4 \%)$ and located in the anterior circulation (80.5\%). Hunt \& Hess Grades I-III and modified Fisher CT grades 1-2 made up 77.2\% and $49.2 \%$, respectively, of the study population. Clinical vasospasm and DCI occurred in $22.8 \%$ and $21.2 \%$, respectively. Favorable functional outcome (mRS 0-2) at hospital discharge and last follow-up was achieved in $47.7 \%$ and $61.7 \%$ of patients, respectively (Table 2 ).

\section{Association of Endothelin SNPs and aSAH}

All SNPs were in Hardy-Weinberg equilibrium with the exception of rs2070699 in patients $(\mathrm{p}=0.001)$ and controls $(p=0.007)$, rs1801708 in patients $(p<0.001)$ and controls $(p=0.002)$, and rs3818416 in controls $(p=0.035$; Table 3). In multivariate logistic regression analysis, the TG (odds ratio [OR] 2.102, 95\% confidence interval [CI] $1.048-4.218, \mathrm{p}=0.036)$ and TT genotypes (OR 7.884, 95\% CI $1.003-61.995, \mathrm{p}=0.05)$ of ENDI T/G SNP (rs1800541) were significantly associated with aSAH along with older age, African American race, and antithrombotic use (Table 4).

\section{Associations of Endothelin SNPs and Clinical Course After aSAH}

In multivariate logistic regression analysis, there was a dominant effect of the $\mathrm{G}$ allele (CG/GG genotypes; OR 4.617, 95\% CI 1.311-16.262, $\mathrm{p}=0.017$ ) of EDNRA G/C SNP (rs5335) on clinical vasospasm. Other predictors of clinical vasospasm were African American race (OR $0.318,95 \%$ CI $0.128-0.795, \mathrm{p}=0.014)$ and higher Hunt and Hess grade (OR 1.861, 95\% CI 1.274-2.716, $\mathrm{p}=0.001)$. DCI was associated with higher Hunt \& Hess grade (OR $1.761,95 \%$ CI $1.077-2.881, \mathrm{p}=0.024)$ and higher modified Fisher CT grade (OR 1.867, 95\% CI 1.099-3.172, $\mathrm{p}=$ 0.021), but none of the endothelin SNPs. Functional outcome at follow-up was associated with ischemic vascular disease (OR 188.109, 95\% CI 9.879-3581.984, p < 0.001), higher Hunt and Hess grade (OR 4.384, 95\% CI 1.734$11.085, \mathrm{p}=0.002$ ), higher modified Fisher grade (OR $3.392,95 \%$ CI $1.062-10.838, \mathrm{p}=0.039)$, larger aneurysm size (OR 1.192, 95\% CI 1.005-1.413, $\mathrm{p}=0.043$ ), and rebleeding (OR 62.005, 95\% CI 3.037-1265.997, $\mathrm{p}=0.007$ ). Endothelin SNPs did not predict unfavorable outcome at hospital discharge or last follow-up (Table 5).

\section{Discussion}

The present study analyzed common endothelin SNPs and their association with aSAH and its sequelae. The T allele of the END1 T/G SNP (rs1800541) was associated with aSAH when compared with controls. The $\mathrm{G}$ allele of the EDNRA G/C SNP (rs5335) was associated with clinical vasospasm. This represents the first investigation of a majority of common endothelin SNPs in the context of aSAH.

\section{Endothelin, Cerebral Aneurysm Development, and Cerebral Vasospasm}

END1 and its receptors have been known to play a significant role in cerebral aneurysm development. ${ }^{15}$ END1 is produced by vascular endothelial cells and is a potent vasoconstrictor that mediates its effects via 2 receptor subtypes, EDNRA and ENDRB. EDNRA is predominantly found on vascular smooth muscle cells of the cerebral vasculature and regulates vasoconstriction and vascular smooth muscle cell proliferation. ${ }^{21}$ The interplay of END1, ENDRA, and ENDRB is critically important for the regulation of vasoconstriction and vasodilatation in response to hemodynamic stress. Endothelin also helps regulate nitric oxide (NO) and alterations in NO SNPs have been associated with aneurysm formation and vasospasm following aSAH. ${ }^{13,14,20}$ The $\mathrm{G}$ allele of the EDNRA G/C SNP has been associated with hypertension. ${ }^{18}$ In the setting of aSAH, the cerebrovascular circulation of homo- and heterozygotes for the $\mathrm{G}$ allele may be more susceptible to the circulating END1 resulting in vasoconstriction and clinical vasospasm mediated at the receptor level. Elevated levels of END1 in CSF and plasma were found in aSAH patients with cerebral vasospasm and DCI. ${ }^{4,12}$ Hemolysis of SAH induces END1 production in activated mononuclear leukocytes. ${ }^{4}$ These discoveries and a number of precursor trials led to the design of the Clazosentan to Overcome Neurological Ischemia and Infarct Occurring after Subarachnoid Hemorrhage (CONSCIOUS)-2 trial, 
TABLE 2. Patient and control characteristics

\begin{tabular}{|c|c|c|c|}
\hline Characteristic & aSAH (\%) & $\begin{array}{l}\text { Controls } \\
(\%)\end{array}$ & $\begin{array}{c}\mathrm{p} \\
\text { Value }\end{array}$ \\
\hline No. of patients & 149 & 50 & \\
\hline Mean age \pm SD (yrs) & $54.9 \pm 12.5$ & $50.6 \pm 18.6$ & 0.07 \\
\hline \multicolumn{4}{|l|}{ Race } \\
\hline Caucasian & $85(57.0)$ & $41(82)$ & 0.003 \\
\hline African American & $60(40.3)$ & $7(14)$ & \\
\hline Other & $4(2.7)$ & $2(4)$ & \\
\hline \multicolumn{4}{|l|}{ Sex } \\
\hline Male & $35(23.5)$ & $18(36)$ & 0.086 \\
\hline Female & $114(76.5)$ & $32(64)$ & \\
\hline Ischemic vascular disease & $13(8.7)$ & $8(16)$ & 0.153 \\
\hline Hypertension & $90(60.4)$ & $20(40)$ & 0.013 \\
\hline \multicolumn{4}{|l|}{ Antithrombotics } \\
\hline None & $132(88.6)$ & $39(78.0)$ & 0.044 \\
\hline Antiplatelets & $14(9.4)$ & $11(22.0)$ & \\
\hline Anticoagulation & $3(2.0)$ & 0 & \\
\hline \multicolumn{4}{|l|}{ Smoking } \\
\hline Never & $58(38.9)$ & $21(42)$ & 0.426 \\
\hline Former & $18(12.1)$ & $9(18)$ & \\
\hline Current & $73(49)$ & $20(40)$ & \\
\hline $\begin{array}{l}\text { Family history of cerebral } \\
\text { aneurysms }\end{array}$ & $14(9.4)$ & $0(0)$ & 0.025 \\
\hline $\begin{array}{l}\text { Mean days for symptom onset } \\
\text { to admission } \pm \text { SD }\end{array}$ & $0.9 \pm 2.7$ & & \\
\hline \multicolumn{4}{|l|}{ Aneurysm size (mm) } \\
\hline$<7$ & $93(62.4)$ & & \\
\hline $7-12$ & $49(32.9)$ & & \\
\hline $13-24$ & $6(4.0)$ & & \\
\hline$\geq 25$ & $1(0.7)$ & & \\
\hline \multicolumn{4}{|l|}{ Location } \\
\hline Anterior & $120(80.5)$ & & \\
\hline Posterior & $29(19.5)$ & & \\
\hline \multicolumn{4}{|l|}{ Hunt \& Hess grade } \\
\hline$|-|||$ & $115(77.2)$ & & \\
\hline IV-V & $34(22.8)$ & & \\
\hline \multicolumn{4}{|l|}{ Fisher grade } \\
\hline $1-2$ & $23(15.4)$ & & \\
\hline $3-4$ & $126(84.6)$ & & \\
\hline \multicolumn{4}{|l|}{ Modified Fisher grade* } \\
\hline $1-2$ & $59(49.2)$ & & \\
\hline $3-4$ & $61(50.8)$ & & \\
\hline \multicolumn{4}{|l|}{ Hijdra scale* } \\
\hline 0 & $29(24.2)$ & & \\
\hline 1 & $10(8.3)$ & & \\
\hline 2 & $24(20.0)$ & & \\
\hline 3 & $20(16.7)$ & & \\
\hline 4 & $7(5.8)$ & & \\
\hline 5 & $4(3.3)$ & & \\
\hline 6 & $11(9.2)$ & & \\
\hline 7 & $5(4.2)$ & & \\
\hline 8 & $4(3.3)$ & & \\
\hline 9 & 0 & & \\
\hline 10 & $5(4.2)$ & & \\
\hline 11 & $1(0.8)$ & & \\
\hline
\end{tabular}

» CONTINUED FROM PREVIOUS COLUMN

TABLE 2. Patient and control characteristics

\begin{tabular}{|c|c|c|c|}
\hline Characteristic & aSAH (\%) & $\begin{array}{l}\text { Controls } \\
(\%)\end{array}$ & $\begin{array}{c}\mathrm{p} \\
\text { Value }\end{array}$ \\
\hline \multicolumn{4}{|l|}{ Treatment† } \\
\hline Microsurgical clipping & $76(52.4)$ & & \\
\hline Endovascular treatment & $69(47.6)$ & & \\
\hline Rebleeding & $7(4.7)$ & & \\
\hline Clinical vasospasm & $34(22.8)$ & & \\
\hline DCl & $31(21.2)$ & & \\
\hline Hyponatremia & $56(37.6)$ & & \\
\hline $\begin{array}{l}\text { Infection (blood stream, pneu- } \\
\text { monia, urinary tract) }\end{array}$ & $61(40.9)$ & & \\
\hline Ventriculitis & $4(2.7)$ & & \\
\hline $\begin{array}{l}\text { Antiepileptic drug administra- } \\
\text { tion }\end{array}$ & $62(41.6)$ & & \\
\hline Mean ICU stay \pm SD (days) & $11.9 \pm 7.9$ & & \\
\hline Mean hospital stay \pm SD (days) & $15.9 \pm 11.3$ & & \\
\hline \multicolumn{4}{|l|}{ Discharge mRS score } \\
\hline $0-2$ & $71(47.7)$ & & \\
\hline $3-6$ & $78(52.3)$ & & \\
\hline \multicolumn{4}{|l|}{ mRS score at last follow-up } \\
\hline $0-2$ & $92(61.7)$ & & \\
\hline $3-6$ & $57(38.3)$ & & \\
\hline $\begin{array}{l}\text { Mean length of follow-up } \pm \text { SD } \\
\quad \text { (days) }\end{array}$ & $249.7 \pm 187.8$ & & \\
\hline
\end{tabular}

a randomized, double-blind, placebo-controlled, Phase 3 study assessing the efficacy of clazosentan in patients in whom the ruptured aneurysm was secured by microsurgical clipping. ${ }^{16}$ The CONSCIOUS-3 trial, including patients treated with endovascular coil embolization, was halted prematurely after CONSCIOUS-2 failed to show a benefit in terms of all-cause mortality and vasospasmrelated morbidity at 6 weeks. ${ }^{17}$ Failure of the trial was attributed to beneficial effects of rescue therapy for angiographic vasospasm that was used more frequently in the placebo group and may have mitigated benefits of clazosentan. Successful rescue therapy in the present study may have also decreased the incidence of DCI and explain the lack of associations of the EDNRA G/C SNP with DCI. Also, mechanisms other than large vessel vasospasm may result in delayed ischemic neurological deficit, DCI, and poor functional outcome. Whereas angiographic vasospasm was significantly decreased by clazosentan in CONSCIOUS-1, microvascular processes such as microthromboembolism, microcirculatory dysfunction, cortical spreading ischemia, and delayed neuronal injury contributing to aforementioned outcome measures may have not been affected.$^{16}$ Lastly, polymorphisms in genes encoding END1 and endothelin receptors or adjacent regulatory regions may change their biological characteristics and alter their response to a drug such as clazosentan. 
TABLE 3. Genotype frequencies of endothelin SNPs

\begin{tabular}{|c|c|c|c|}
\hline Polymorphism & aSAH (\%) & Controls (\%) & $p$ Value \\
\hline rs1800541 & & & 0.016 \\
\hline \multicolumn{4}{|l|}{ Genotype } \\
\hline GG & $69(46.3)$ & $34(68.0)$ & \\
\hline TG & $64(43.0)$ & $15(30.0)$ & \\
\hline TT & $16(10.7)$ & $1(2)$ & \\
\hline HWE ( $p$ value) & 0.840 & 0.656 & \\
\hline rs2070699 & & & 0.111 \\
\hline \multicolumn{4}{|l|}{ Genotype } \\
\hline GG & $117(78.5)$ & $33(66.0)$ & \\
\hline GT & $25(16.8)$ & $11(22.0)$ & \\
\hline TT & $7(4.7)$ & $6(12.0)$ & \\
\hline HWE ( $p$ value) & 0.001 & 0.007 & \\
\hline rs5370 & & & 0.33 \\
\hline \multicolumn{4}{|l|}{ Genotype } \\
\hline GG & $88(59.0)$ & $35(70.0)$ & \\
\hline GT & $56(37.6)$ & $13(26.0)$ & \\
\hline TT & $5(3.4)$ & $2(4)$ & \\
\hline HWE (p value) & 0.273 & 0.578 & \\
\hline rs1801708 & & & 0.571 \\
\hline \multicolumn{4}{|l|}{ Genotype } \\
\hline$A A$ & $1(0.7)$ & 0 & \\
\hline$A G$ & $99(66.4)$ & $30(60)$ & \\
\hline GG & $49(32.9)$ & $20(40)$ & \\
\hline HWE ( $p$ value) & $<0.001$ & 0.002 & \\
\hline rs5333* & & & 0.615 \\
\hline \multicolumn{4}{|l|}{ Genotype } \\
\hline $\mathrm{CC}$ & $19(12.9)$ & $9(18.4)$ & \\
\hline CT & $61(41.5)$ & $18(36.7)$ & \\
\hline TT & $67(45.6)$ & $22(44.9)$ & \\
\hline HWE ( $p$ value) & 0.389 & 0.142 & \\
\hline rs5335* & & & 0.058 \\
\hline \multicolumn{4}{|l|}{ Genotype } \\
\hline $\mathrm{CC}$ & $30(20.4)$ & $17(34.7)$ & \\
\hline CG & $70(47.6)$ & $20(40.8)$ & \\
\hline GG & $47(32.0)$ & $12(24.5)$ & \\
\hline HWE ( $p$ value) & 0.674 & 0.220 & \\
\hline rs3818416* & & & 0.34 \\
\hline \multicolumn{4}{|l|}{ Genotype } \\
\hline $\mathrm{CC}$ & $15(10.2)$ & $6(12.2)$ & \\
\hline $\mathrm{CA}$ & $56(38.1)$ & $13(26.5)$ & \\
\hline$A A$ & $76(51.7)$ & $30(61.3)$ & \\
\hline HWE ( $p$ value) & 0.335 & 0.035 & \\
\hline rs5351* & & & 0.27 \\
\hline \multicolumn{4}{|l|}{ Genotype } \\
\hline $\mathrm{TT}$ & $51(34.7)$ & $12(24.5)$ & \\
\hline TG & 65 (44.2) & $28(57.1)$ & \\
\hline GG & $31(21.1)$ & $9(18.4)$ & \\
\hline HWE ( $p$ value) & 0.230 & 0.303 & \\
\hline
\end{tabular}

HWE $=$ Hardy-Weinberg equilibrium

* Alleles were not available for 2 patients with aSAH and 1 control.
TABLE 4. Predictors of aSAH in multivariate logistic regression analysis

\begin{tabular}{lll}
\hline \multicolumn{1}{c}{ Variable } & \multicolumn{1}{c}{ OR $(95 \% \mathrm{Cl})$} & $\mathrm{p}$ Value \\
\hline Older age & $1.031(1.006-1.058)$ & 0.016 \\
\hline African American & $3.293(1.329-8.158)$ & 0.01 \\
\hline Antithrombotics & $0.279(0.106-0.735)$ & 0.01 \\
\hline TG genotype (rs1800541) & $2.102(1.048-4.218)$ & 0.036 \\
\hline TT genotype (rs1800541) & $7.884(1.003-61.995)$ & 0.05 \\
\hline
\end{tabular}

\section{Endothelin SNPs and aSAH}

Endothelin SNPs have not been extensively studied in the setting of aSAH. Through a genome-wide association study and imputation analysis, 4 SNPs, 1 in an intron (rs17612742) and 3 upstream (rs6841581, 1878406, and rs6842241) of the EDNRA gene on chromosome 4, were found to be to be associated with cerebral aneurysm development. ${ }^{15}$ Using cell line material, potential effects of these SNPs on the transcriptional activity of ENDRA were studied. A dual-luciferase reporter assay was used to detect differences in the transcriptional activity and found significantly lower activity of the $\mathrm{G}$ allele of rs6841581 when compared with the A allele. This suggests that the $5^{\prime}$ flanking region of the ENDRA gene containing rs6841581 might function as a transcriptional repressor and that this SNP is a functional variant that may be involved in cerebral aneurysm development. ${ }^{15}$ Whether the $\mathrm{G}$ allele of the EDNRA G/C SNP (rs5335) confers similar functional alterations relevant to clinical vasospasm remains to be determined.

Gallek et al. examined a number of other END1 and endothelin receptor SNPs and their association with negative outcome after aSAH. ${ }^{8}$ Similar to the present study, their analysis included rs5370, or Lys198Asn, a known functional SNP in the END1 gene associated with differences in vascular reactivity, ${ }_{11}$ and a number of other tagging SNPs of ENDI, ENDRA, and ENDRB. Neither their study nor the present study found any association of rs5370 with aSAH or its sequelae. They did, however, identify a trend between the END1 A/G SNP (rs6912834) and angiographic vasospasm. There were also associations found between two EDNRB SNPs (rs9574124 and rs3027111) and poor functional outcomes at 3 months, with the ENDRB C/T SNP (rs3027111) being associated with a higher risk of mortality at 3 months. Gallek et al. did not collect samples from a control group, but compared their patients with aSAH to a representative control population from the HapMap database (https://www.ncbi. nlm.nih.gov/probe/docs/projhapmap/). The distribution of genotypes between study and control patients did not differ and the authors concluded that common endothelin SNPs did not play a role in aneurysm development and aSAH. ${ }^{8}$ In the present study, the T allele of the ENDI T/G SNP (rs1800541) conferred a risk for aSAH even after controlling for racial differences and other potential confounders between patients with aSAH and controls. This and other studies may result in the development of a screening tool to identify patients with cerebral aneu- 
TABLE 5. Predictors of outcome measures in aSAH in multivariate logistic regression analysis

\begin{tabular}{lcc}
\hline \multicolumn{1}{c}{ Predictor } & OR $(95 \%$ Cl) & p Value \\
\hline Clinical vasospasm & & \\
\hline African American & $0.318(0.128-0.795)$ & 0.014 \\
\hline Higher Hunt \& Hess grade & $1.861(1.274-2.716)$ & 0.001 \\
\hline $\begin{array}{c}\text { Dominant effect G allele (CG } \\
\text { \& GG vs CC; rs5335) }\end{array}$ & $4.617(1.311-16.262)$ & 0.017 \\
\hline DCl & & \\
\hline Higher Hunt \& Hess grade & $1.761(1.077-2.881)$ & 0.024 \\
\hline Higher modified Fisher grade & $1.867(1.099-3.172)$ & 0.021 \\
\hline Rebleeding & $10.773(1.027-113.050)$ & 0.047 \\
\hline Hyponatremia & $0.312(0.103-0.941)$ & 0.039 \\
\hline $\begin{array}{c}\text { Unfavorable outcome at dis- } \\
\text { charge (mRS score 3-6) }\end{array}$ & $1.631(1.118-2.379)$ & 0.011 \\
\hline $\begin{array}{c}\text { Days for symptom onset to } \\
\text { admission }\end{array}$ & $18.077(3.456-94.546)$ & 0.001 \\
\hline Higher Hunt \& Hess grade & $2.280(1.162-4.474)$ & 0.017 \\
\hline Higher modified Fisher \\
$\quad$ grade
\end{tabular}

rysms at risk for aSAH, and patients with aSAH who are at risk for developing clinical vasospasm, DCI, and unfavorable functional outcome.

\section{Limitations of the Study}

The small sample size is a limitation as larger samples are preferred for association studies. As such, the findings should be interpreted with caution until larger data sets are available for analysis. The study did not assess whether endothelin SNPs altered transcription or the biological character of the proteins encoded. Some SNPs were not in Hardy-Weinberg equilibrium. This may be a result of genetic drift or variation in the relative frequency of different genotypes in a small population due to the chance that particular genes disappear as individuals die or do not reproduce. Certain genotypes may also represent a disadvantage to survive aSAH or result in a decreased risk for cerebral aneurysm formation or rupture. Another limitation is the determination of clinical vasospasm, i.e., its diagnosis is based on the clinical process as a whole, including the neurological examination and corroborating imaging evidence, and as such is vulnerable to subjective opinion.

\section{Conclusions}

Common endothelin SNPs were found to be associated with aSAH and its sequelae. The T allele of the ENDI T/G SNP (rs1800541) was associated with aSAH. The G allele of the EDNRA G/C SNP (rs5335) was associated with clinical vasospasm. Further studies are required to elucidate the relevant pathophysiology and its potential implication in the treatment of patients with aSAH.

\section{Acknowledgments}

We would like to thank R. Shane Tubbs and Mohammadali M. Shoja for their contribution to the conception of the CARAS study. We would like to thank the participants in this study and the efforts of the neurosurgical research coordinators at Inova Health System for their work and contribution to the CARAS Study. We would also like to thank the Brain Aneurysm Foundation and family of Timothy P. Susco for their generous support of the CARAS Study.

\section{References}

1. Bruno A, Akinwuntan AE, Lin C, Close B, Davis K, Baute V, et al: Simplified modified Rankin scale questionnaire: reproducibility over the telephone and validation with quality of life. Stroke 42:2276-2279, 2011

2. Connolly ES Jr, Rabinstein AA, Carhuapoma JR, Derdeyn $\mathrm{CP}$, Dion J, Higashida RT, et al: Guidelines for the management of aneurysmal subarachnoid hemorrhage: a guideline for healthcare professionals from the American Heart Association/American Stroke Association. Stroke 43:1711-1737, 2012

3. Dankbaar JW, Slooter AJ, Rinkel GJ, Schaaf IC: Effect of different components of triple-H therapy on cerebral perfusion in patients with aneurysmal subarachnoid haemorrhage: a systematic review. Crit Care 14:R23, 2010

4. Fassbender K, Hodapp B, Rossol S, Bertsch T, Schmeck J, Schütt S, et al: Endothelin-1 in subarachnoid hemorrhage: An acute-phase reactant produced by cerebrospinal fluid leukocytes. Stroke 31:2971-2975, 2000

5. Foreman PM, Chua M, Harrigan MR, Fisher WS III, Tubbs RS, Shoja MM, et al: Antifibrinolytic therapy in aneurysmal subarachnoid hemorrhage increases the risk for deep venous thrombosis: a case-control study. Clin Neurol Neurosurg 139:66-69, 2015

6. Foreman PM, Chua M, Harrigan MR, Fisher WS III, Vyas NA, Lipsky RH, et al: Association of nosocomial infections with delayed cerebral ischemia in aneurysmal subarachnoid hemorrhage. J Neurosurg 125:1383-1389, 2016

7. Foreman PM, Chua MH, Harrigan MR, Fisher WS III, Tubbs RS, Shoja MM, et al: External validation of the Practical Risk Chart for the prediction of delayed cerebral ischemia following aneurysmal subarachnoid hemorrhage. J Neurosurg [epub ahead of print May 13, 2016; DOI: 10.3171/2016.1.JNS152554]

8. Gallek M, Alexander S, Crago E, Sherwood P, Horowitz M, Poloyac S, et al: Endothelin-1 and endothelin receptor gene variants and their association with negative outcomes following aneurysmal subarachnoid hemorrhage. Biol Res Nurs 15:390-397, 2013

9. Griessenauer CJ, Tubbs RS, Foreman PM, Chua MH, Vyas NA, Lipsky RH, et al: Association of renin-angiotensin system genetic polymorphisms and aneurysmal subarachnoid hemorrhage. J Neurosurg [epub ahead of January 20, 2017; DOI: $10.3171 / 2016.9 . J N S 161593]$ 
10. Griessenauer CJ, Tubbs RS, Foreman PM, Chua MH, Vyas NA, Lipsky RH, et al: Associations of renin-angiotensin system genetic polymorphisms and clinical course after aneurysmal subarachnoid hemorrhage. J Neurosurg [epub ahead of print June 10, 2016; DOI: 10.3171/2016.4.JNS16409]

11. Iglarz M, Benessiano J, Philip I, Vuillaumier-Barrot S, Lasocki S, Hvass U, et al: Preproendothelin-1 gene polymorphism is related to a change in vascular reactivity in the human mammary artery in vitro. Hypertension 39:209-213, 2002

12. Juvela S: Plasma endothelin concentrations after aneurysmal subarachnoid hemorrhage. J Neurosurg 92:390-400, 2000

13. Khurana VG, Sohni YR, Mangrum WI, McClelland RL, O'Kane DJ, Meyer FB, et al: Endothelial nitric oxide synthase gene polymorphisms predict susceptibility to aneurysmal subarachnoid hemorrhage and cerebral vasospasm. J Cereb Blood Flow Metab 24:291-297, 2004

14. Ko NU, Rajendran P, Kim H, Rutkowski M, Pawlikowska L, Kwok PY, et al: Endothelial nitric oxide synthase polymorphism $(-786 \mathrm{~T}>\mathrm{C})$ and increased risk of angiographic vasospasm after aneurysmal subarachnoid hemorrhage. Stroke 39:1103-1108, 2008

15. Low SK, Takahashi A, Cha PC, Zembutsu H, Kamatani N, Kubo M, et al: Genome-wide association study for intracranial aneurysm in the Japanese population identifies three candidate susceptible loci and a functional genetic variant at EDNRA. Hum Mol Genet 21:2102-2110, 2012

16. Macdonald RL, Higashida RT, Keller E, Mayer SA, Molyneux A, Raabe A, et al: Clazosentan, an endothelin receptor antagonist, in patients with aneurysmal subarachnoid haemorrhage undergoing surgical clipping: a randomised, doubleblind, placebo-controlled phase 3 trial (CONSCIOUS-2). Lancet Neurol 10:618-625, 2011

17. Macdonald RL, Higashida RT, Keller E, Mayer SA, Molyneux A, Raabe A, et al: Randomized trial of clazosentan in patients with aneurysmal subarachnoid hemorrhage undergoing endovascular coiling. Stroke 43:1463-1469, 2012

18. Rahman T, Baker M, Hall DH, Avery PJ, Keavney B: Common genetic variation in the type A endothelin-1 receptor is associated with ambulatory blood pressure: a family study. J Hum Hypertens 22:282-288, 2008

19. Rosalind Lai PM, Du R: Role of genetic polymorphisms in predicting delayed cerebral ischemia and radiographic vasospasm after aneurysmal subarachnoid hemorrhage: a metaanalysis. World Neurosurg 84:933-944, 941.e1-941.e2, 2015
20. Starke RM, Kim GH, Komotar RJ, Hickman ZL, Black EM, Rosales MB, et al: Endothelial nitric oxide synthase gene single-nucleotide polymorphism predicts cerebral vasospasm after aneurysmal subarachnoid hemorrhage. J Cereb Blood Flow Metab 28:1204-1211, 2008

21. Yu JC, Pickard JD, Davenport AP: Endothelin ETA receptor expression in human cerebrovascular smooth muscle cells. Br J Pharmacol 116:2441-2446, 1995

22. Zhang L, Sui R: Effect of SNP polymorphisms of EDN1, EDNRA, and EDNRB gene on ischemic stroke. Cell Biochem Biophys 70:233-239, 2014

\section{Disclosures}

The authors report no conflict of interest concerning the materials or methods used in this study or the findings specified in this paper.

\section{Author Contributions}

Conception and design: Griessenauer. Acquisition of data: Griessenauer, Foreman, Vyas. Analysis and interpretation of data: Griessenauer, Starke, Foreman, Lipsky, Lin. Drafting the article: Griessenauer, Starke. Critically revising the article: Griessenauer, Starke, Foreman, Hendrix, Pittet, Mathru. Reviewed submitted version of manuscript: Griessenauer, Foreman, Hendrix. Approved the final version of the manuscript on behalf of all authors: Griessenauer. Statistical analysis: Griessenauer, Starke. Administrative/technical/material support: Griessenauer, Pittet, Mathru. Study supervision: Griessenauer, Harrigan, Fisher, Walters, Pittet, Mathru.

\section{Supplemental Information \\ Current Affiliations}

Dr. Griessenauer: Department of Neurosurgery, Geisinger Health System, Danville, PA

\section{Correspondence}

Christoph J. Griessenauer, Beth Israel Deaconess Medical Center, Harvard Medical School, 110 Francis St., Ste. 3B, Boston, MA 02215. email: christoph.griessenauer@gmail.com. 